
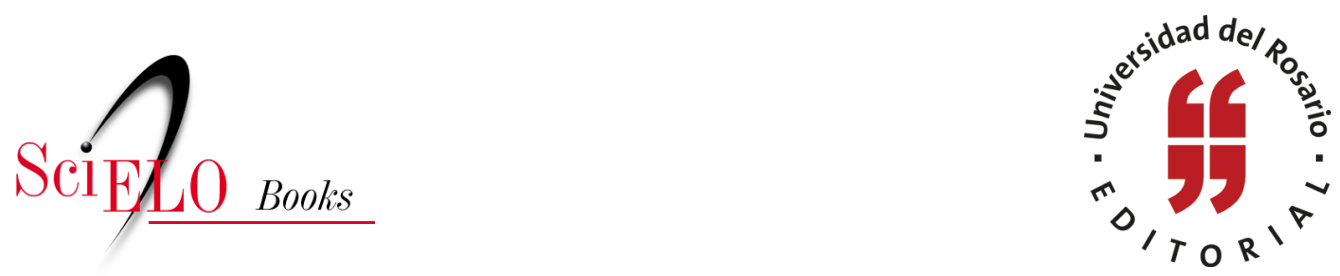

\title{
Realidad, mito y alegoría de la nación en Y tu mamá también (2001)
}

\author{
Christian Wehr
}

\section{SciELO Books / SciELO Livros / SciELO Libros}

WEHR, C. Realidad, mito y alegoría de la nación en Y tu mamá también (2001). In: SCHUSTER, S., ed. La nación expuesta. Cultura visual y procesos de formación de la nación en América Latina [online]. Bogotá: Editorial Universidad del Rosario, 2014, pp. 229-238. Textos de ciencias humanas collection. ISBN: 978-958-738-524-3. https://doi.org/10.7476/9789587385243.0012.

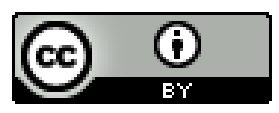

All the contents of this work, except where otherwise noted, is licensed under a Creative Commons Attribution 4.0 International license.

Todo o conteúdo deste trabalho, exceto quando houver ressalva, é publicado sob a licença Creative Commons Atribição 4.0.

Todo el contenido de esta obra, excepto donde se indique lo contrario, está bajo licencia de la licencia Creative Commons Reconocimento 4.0. 


\section{Realidad, mito y alegoría de la nación en Y tu mamá también (2001)}

Christian Wehr

Universität Würzburg

Dos películas estrenadas en el 2001 marcaron el inicio de un nuevo cine mexicano que fusiona temas regionales con la dinámica de la globalización: Y tu mamá también, de Alfonso Cuarón, y Amores perros, de Alejandro González Iñárritu. Los éxitos internacionales de ambas obras se explican, entre otros motivos, por la adaptación de estructuras formales y genéricas que no existían antes en el cine mexicano. González Inárritu perfecciona un estilo episódico inspirado en las películas de Robert Altman, mientras que Cuarón recurre al género norteamericano del roadmovie, combinando elementos de la comedia de adolescentes en la narración de las aventuras de dos jóvenes durante sus vacaciones de verano. La simplicidad de la trama es engañosa, porque esconde una complejidad desconcertante: por medio del tema de la adolescencia, Cuáron pone en escena una gran variedad de alusiones latentes a la historia, a la mitología y a la situación política de la nación mexicana (Baer 2004; Lahr-Vivaz 2006).

En este trabajo intento sistematizar los diferentes niveles semánticos de la película. Para tal fin, comienzo con un breve resumen de la trama que me permite analizar en total cuatro aspectos diferenciados. Cada uno de ellos se encuentra relacionado de manera específica con el tema de la nación, es decir, con su mitología, sus estereotipos y su actualidad política. Se trata en particular del carácter iniciático del viaje, de la revisión de los roles de género, de la actualización y transformación de algunos mitos fundacionales, del sentido alegórico de la trama y de la constela- 
ción básica. Los diferentes sentidos convergen en la construcción fílmica de una nación en proceso de transición o, en términos alegóricos, de un país adolescente.

\section{Un roadmovie mexicano}

La situación inicial retoma el modelo hollywoodense de la comedia de adolescentes. Según el esquema estereotipado del género, vemos a dos jóvenes de diecisiete o dieciocho años de edad, originarios del Distrito Federal (D. F.), al comienzo de sus vacaciones de verano. Se trata de Tenoch Iturbide (interpretado por Diego Luna), hijo de un político de alto rango, y su amigo Julio Zapata, representado por Gael García Bernal, en su segundo gran papel de cine posterior a Amores perros. Julio es de clase media y comparte con su mejor amigo los placeres pubertarios: fuman marihuana, salen a divertirse, se emborrachan en las fiestas y se masturban a dúo.

Cuando sus novias se van de vacaciones a Europa, Julio y Tenoch aprovechan la libertad para buscar aventuras eróticas. Y a la primera oportunidad que tienen es crucial cuando, en una boda familiar, los jóvenes conocen a Luisa Cortés, la esposa del primo de Tenoch. A pesar de ser diez años mayor, los amigos la invitan a acompañarlos en un viaje espontáneo hacia la "Boca del Cielo", una playa en la bahía de Huatulco, situada en el estado de Oaxaca. Finalmente, Luisa acepta la invitación por dos motivos: por un lado, está harta de la infidelidad notoria de su marido y, por otro, sabe desde hace poco tiempo que tiene un cáncer mortal. Así, el trío parte hacia el sur.

Durante el viaje espontáneo se revelan sucesivamente diversos secretos. Julio confiesa que se acostó con la novia de su mejor amigo, quien, por su parte, también había hecho lo mismo con la novia de Julio. A su vez, se establece entre ellos un triángulo amoroso: Luisa tiene relaciones sexuales con ambos amigos, primero con Tenoch y luego con Julio. La gran crisis mimética — para emplear un término de René Girard (1978 y 1982) — culmina en una pelea dramática que Luisa logra, no obstante, controlar. Finalmente, los tres llegan a la Boca del Cielo, donde se encuentran al pescador Jesús Chuy Carranza; los tres pasarán días idílicos con él y su familia.

La última noche del viaje empieza con una cena que está filmada sin cortes, en un plano secuencia de casi ocho minutos. Regresado al hotel, borrachos, los tres tienen un baile erótico; Luisa se va y los amigos comparten su primera y última experiencia gay. Este suceso no es mencionado por ellos nunca más. Por la mañana, empacan mudos y vuelven a la ciudad de México. Un año después, en el 2000, al tiempo en que el Partido Revolucionario Institucional (PRI) perdía por 
primera vez las elecciones en 71 años, Julio se cruza a Tenoch cuando se encontraba de camino al dentista. La película termina con una última conversación en la cual Tenoch le comenta a Julio que Luisa había muerto de cáncer al mes siguiente del viaje a Oaxaca. Finalmente, una voz en off nos añade que los amigos no volvieron a verse nunca más.

Y tu mamá también es uno de los primeros roadmovies en la historia del cine mexicano, un género relativamente nuevo de origen norteamericano. Su gran tema es el viaje - en un sentido literal y figurativo a la vez-. La estética cinematográfica muestra claramente la influencia del neorrealismo italiano, con películas que se caracterizan por un estilo documental, donde incluso se improvisan diálogos y escenas enteras. Por un lado, en un nivel ético-semántico, el movimiento continuo a través de una topología real se corresponde muchas veces con una narración de experiencias límite. Por otro, la dinámica transgresora y subversiva del roadmovie revela afinidades con el género de la picaresca (Grob y Klein 2006).

Considerando todas estas características básicas, Y tu mamá también se constituye en un ejemplo destacado. Los protagonistas se sitúan en varias experiencias liminales, es decir, en las oposiciones entre legalidad e ilegalidad, sexualidad 'oficial' y subversiva, clase alta y baja, campo y ciudad, Europa y Centroamérica, política socialista y conservadora, destino cómico y trágico, e incluso entre vida y muerte. La contradicción más indiscutible es posiblemente la transformación del machismo que caracteriza el comportamiento de los jóvenes, en un deseo homosexual que se manifiesta solamente una vez, pero de manera irresistible. Además, la serie de oposiciones fundamentales dan a conocer un paralelismo fundamental: Cuarón construye sutilmente una analogía entre la adolescencia como fase de individuación y la situación inestable y transitoria de la nación. Ontogénesis y filogénesis se corresponden mutuamente. ${ }^{1}$

\section{El viaje como iniciación: utopía y rito de pasaje}

El estilo neorrealista y documental del roadmovie está vinculado de manera sugestiva con toda una serie de subtextos míticos y alegóricos. Como lo señala el romanista Friedrich Wolfzettel en sus estudios sobre la literatura de viaje, este tema arcaico se relaciona, desde la Odisea, con significados míticos y, en particular, con ritos de pasaje (2003, 11-39). En la trama de Y tu mamá también se superponen varios temas

1 En la terminología del psicoanalista suizo Carl G. Jung se trata del principio de sincronicidad (Synchronizität). Véase Jung y Pauli (1952). 
iniciáticos. El más evidente es el de la sexualidad: Luisa, la mujer experimentada, cumple el papel de una mediadora que introduce a los jóvenes a la sexualidad adulta.

Otra estructura iniciática se manifiesta en el destino del viaje, la playa llamada Boca del Cielo. Las connotaciones bíblicas del nombre aluden al mito medieval del paraíso terrenal y a sus incontables búsquedas (Börner 1984; Grimm 1977). Este topos tiene una larga tradición en la literatura latinoamericana: desde los diarios de viaje de Colón y las crónicas de los conquistadores hasta la novela del siglo xx. Sus connotaciones escatológicas se concretan cuando se nos dice que el pescador de la playa mítica —su trabajo alude al primero de los apóstoles— se llama Jesús Carranza. En esta figura se refleja el doble sentido del viaje: entre realismo documental y teleología bíblica. Por una parte, Carranza es un campesino humilde y, por otra, una figura mesiánica que abre las puertas de paraíso (La Boca del Cielo podría ser igualmente una alusión a la muerte cercana de Luisa). Como en el libro del Génesis, la expulsión coincide con una escena de seducción: la experiencia homosexual ocurre en la última noche antes de la partida final. De esta manera, el nivel realista y el sentido alegórico convergen al final para disociarse definitivamente. El esquema arquetípico de la búsqueda alcanza su meta; pero la utopía es efímera, se realiza solamente durante algunos días.

Para resumir, se puede constar que el modelo narrativo del roadmovie y las estructuras iniciáticas del viaje abren un espacio en el cual se relativizan y suspenden los valores tradicionales. Este proceso de desestabilización —incluso liberaciónafecta la concepción de la sexualidad, así como los contrarios políticos y sociales representados por los protagonistas. Aunque el subtexto escatológico evoca una utopía transitoria, el final nos muestra un regreso a las reglas y normas cotidianas. En este sentido, la película es subversiva y reaccionaria a la vez. Quisiera profundizar en esta ambigüedad analizando las escenificaciones del deseo que se manifiestan en una promiscuidad omnipresente.

\section{Transformaciones del deseo: entre el machismo y la homosexualidad}

Las relaciones afectivas entre las figuras están dominadas por un deseo edípico. Se trata de un tema recurrente en la literatura, el pensamiento y el cine de México que está casi siempre vinculado con la ausencia traumática del padre: basta pensar en las obras de Octavio Paz y Juan Rulfo o en las películas mexicanas de Luis Buñuel. En Y tu mamá también, el padre de Luisa falleció en un accidente de coche, el de Julio desapareció cuando tenía cuatro años y el de Tenoch dedica el tiempo a su 
carrera política. Desde una perspectiva freudiana o lacaniana, la falta de autoridad paternal genera un deseo que se caracteriza por una relación identificatoria con el otro: la identificación con la madre persiste si no está limitada por el "no" del padre (Freud 1982a; Lacan 1998, 143-247). En este caso, el fantasma de fusión —como deseo de estar en el lugar del otro- genera afectos contradictorios entre el amor y los celos. Según el estudio clásico de Lacan, esta dinámica identificatoria tiene su origen en el estadio del espejo, en el cual el niño reconoce por primera vez su propio reflejo, al celebrar la aparición de su imagen con gestos de alegría y éxtasis. En una primera fase, esta autoidentificación crea el fundamento de una relación especular con el propio yo (Lacan 1966a). Durante el narcisismo secundario - para emplear el término de Freud - llega a ser la matriz de relaciones imaginarias e identificatorias con los otros (Freud 1982b; Kittler 1977, 147).

Recurriendo al triángulo en Y tumamá también se ve cómo el narcisismo edípico organiza casi todas las relaciones afectivas, sobre todo la confraternidad entre Julio y Tenoch. Su relación oscila permanentemente entre rivalidad e identificación, sensibilidad latente y machismo extrovertido, agresión y atracción sexual. ${ }^{2}$ Por otro lado, cada uno tuvo relaciones sexuales con la novia del otro, tal como Julio y Tenoch se confiesan mutuamente. El quiasmo ilustra perfectamente la estructura mimética del deseo que es, según el aforismo de Lacan, siempre el deseo del otro (Lacan 1966b, 852). La rivalidad edípica determina igualmente la relación de los adolescentes con la española Luisa — una relación que tiene fuertes connotaciones incestuosas-. Este fantasma incestuoso está incluso formulado de manera programática en el título de la película: durante la cena final, Julio cuenta que tuvo sexo con la madre de su mejor amigo Tenoch; la cita "y tu mamá también” es una copia de esta conversación.

En resumen, se puede constar que Luisa cumple un papel sumamente complejo y contradictorio: en primer lugar, es la iniciadora sexual; en segundo, el intocable sustituto de la madre, y en tercer lugar, la heroína trágica condenada a una muerte solitaria. Según la interpretación clásica de Freud, el complejo de Edipo invertido se caracteriza por la identificación con la madre, que genera así el deseo homosexual de ser amado por el padre (Freud 1982a). Luisa subraya muy claramente esta conexión cuando dice que los adolescentes se pelean solamente por ella para no hacer el amor entre ellos. De este modo, la ausencia de la ley paternal crea una

2 Véase con respecto al complejo de intrusión, que oscila entre agresión e identificación, a Lacan (1984, $35-49)$. 
promiscuidad omnipresente. Los amigos compensan esta falta de normas con su propia ética satírica: crean el manifiesto de los charolastras, como Tenoch y Julio se llaman (más adelante vuelvo sobre el significado latente de este título). Se trata del siguiente decálogo pubertario:

No hay honor más grande que ser un charolastra

Cada quien puede hacer de su culo un papalote

Pop mata poesía. Un "toque" al día... la llave de la alegría

No te tirarás a la vieja de otro charolastra

Puto el que le vaya al América

Que muera la moral y que viva la chaqueta

Prohibido casarse con una virgen

Puto el que le vaya al América (se repite porque es reputo el que le vaya al América)

La "neta" es chida pero inalcanzable

Pierde la calidad de charolastra aquel que sea tan culero para romper con alguno de los puntos anteriores. (Cuarón 2001,31:35-32:30)

Después de la gran pelea, Luisa se queda solamente con los jóvenes a condición de que les imponga sus propias reglas, y ello sustituye el manifiesto pubertario por su propio decálogo feminista. Respecto a la concepción de géneros y a la sexualidad, puedo resumir que Cuarón pone en escena de manera lúdica una redefinición -o, por lo menos, una subversión - de los estereotipos nacionales: sustituye el machismo por el deseo gay y una ley matriarcal (Mora 2006, 174-177).

Más allá de esto, veremos que estas motivaciones psicológicas crean el fundamento de un juego abierto y ambivalente con los mitos nacionales. Como lo subrayó Alfonso Cuarón, la película muestra, por medio de sus protagonistas, un país adolescente (Alion 2001, 138).

\section{Los mitos nacionales: constelaciones alegóricas}

Las claves para el entendimiento de esta dimensión colectiva y política son los apellidos y nombres (véanse Acevedo-Muñoz 2004; Saldana-Portillo 2005, 759772). Julio no es solamente de procedencia modesta, sino que se llama Zapata, como el revolucionario mítico. Además, sabemos que su hermana apoya a los rebeldes zapatistas en las batallas sangrientas que tienen lugar en Chiapas. Tenoch, al contrario, es el hijo de un político de alto rango; un representante del PRI que se 
llama Iturbide, como el líder en las guerras de independencia y posterior emperador que combatió a los ejércitos indígenas entre los años veinte y treinta del siglo xIx. Como el narrador explica, su nombre se debe a una identificación populista y oportunista con las culturas autóctonas: al principio, sus padres querían llamarlo Hernán, como el conquistador del siglo XVI.

Si tomamos en serio estos significados figurativos y emblemáticos, la relación entre Tenoch y Julio representa, en un plano alegórico, el antagonismo de las clases sociales y partidos políticos. Sabemos por los estudios de Doris Sommer (1991) que la alegorización de los discursos políticos tiene una larga tradición en la literatura latinoamericana. Es evidente que Alfonso Cuarón recurre a esta técnica literaria. Vimos que la amistad de los adolescentes está marcada por los extremos de un mimetismo fundamental y una concurrencia violenta a la vez. Desde esta perspectiva, su relación intersubjetiva puede interpretarse como la personificación de la situación política del país entre los años ochenta y noventa, particularmente en las disputas entre el PRI y el Frente Democrático Nacional, la coalición de fuerzas políticas mexicanas creada en 1989. Este último representa el antecedente inmediato del Partido de la Revolución Democrática, que fue el resultado de la unión de pequeñas fuerzas políticas de izquierda con una corriente disidente del PRI. El Frente Democrático Nacional tuvo entonces sus mismos orígenes en una vertiente del PRI: una ambivalencia que se refleja implícitamente en la relación de los jóvenes y en la condición social y política de sus familias.

Con la entrada en escena de Luisa, no obstante, se complican las cosas. En un plano alegórico se trata de una figura sumamente compleja. La literatura escrita sobre la película la califica varias veces de personificación de la nación-madre. La rivalidad erótica y afectiva de los adolescentes es entonces la lucha de los partidos por el gobierno del "cuerpo" alegórico de la nación. Más pertinente, sin embargo, me parecen las connotaciones onomásticas de su apellido: Luisa se apellida Cortés. Se refiere directamente a la figura del conquistador $-\mathrm{y}$ con esto igualmente a la Malinche, que era, como Luisa, una mediadora entre las diferentes culturas y partes de la población mexicana- (Acevedo-Muñoz 2004; Saldana-Portillo 2005, 762 y 763). Desde esta perspectiva, la iniciación o mediación sexual sería la alegoría de una fusión entre las oposiciones políticas y sociales representadas por Tenoch y Julio (como sabemos, la alegoría mística de la fusión sexual ya se encuentra en el Antiguo Testamento, aunque no profundiza nuestro análisis en esa dirección). Cuarón evoca tales significados sin confirmarlos definitivamente. Me parece evidente, sin embargo, que la película vincula sutilmente los planos psicológicos, míticos y 
políticos, con el fin de construir una alegoría de la nación a través de los significados alegóricos de los nombres. Cuarón logra maravillosamente evocar esta variedad de sentidos sin sobrecargar el carácter espontáneo e improvisado del roadmovie.

\section{Síntesis: la nación adolescente}

No es este el lugar para ilustrar de qué manera la película pone en escena las diferentes caras de un México casi nunca visto en el cine. Sería necesario analizar el manejo virtuoso de una cámara documental y subjetiva, la técnica sofisticada de cortes discontinuos o los procedimientos de un montaje inspirado por las innovaciones de la nouvelle vague francesa, sobre todo por el cine de Jean-Luc Godard. Tampoco puedo interpretar las funciones de la voz en off, es decir, de un narrador omnisciente que comenta regularmente la historia y sus implicaciones políticas.

Todos estos procedimientos complementan y enmarcan la historia en varios sentidos: muestran escenas de violencia, de pobreza, de tensiones (sociales, culturales y étnicas) o simplemente instantáneas de la vida cotidiana. Para terminar, vuelvo a una alegoría clave que resume y sintetiza los diferentes planos semánticos: se trata de la analogía fundamental entre un país adolescente y la historia de dos jóvenes en la búsqueda de su identidad. Su rivalidad puede entenderse como emblema de una situación política que queda abierta e implícita hasta el fin: solamente en la última escena el narrador explica que el PRI perdió las elecciones por primera vez en 71 años. En este sentido, la adolescencia es la clave figurativa que permite poner en escena a un país que se encuentra en una fase de varias transiciones. Observamos, en una subversión del deseo y de los papeles de géneros, una utopía brevemente vivida en el lugar mítico-escatológico de la Boca del Cielo, la escenificación de un cambio político. Hay que añadir diversos procesos de transculturación: ${ }^{3}$ Tenoch había sido educado por una niñera indígena a la que llamó mamá hasta los cuatro años. En este caso, la cultura autóctona llenó el hueco afectivo en el corazón de la intimidad de la clase alta.

Otro efecto transcultural caracteriza el más original de los juegos onomásticos. Se trata del título de los charolastras que se dan Julio y Tenoch en su manifiesto de adolescentes. El neologismo es efecto de un malentendido transcultural: los amigos escucharon la canción "Space cowboy”, de Steve Miller, en la radio, traducido como "Charro astral” y, finalmente, deformado en "charolastro". Aquí el criterio de

3 Véase con respecto a la categoría de la transculturación Rama (1982) y Pratt (2008, 1-12). 
identidad se debe a un malentendido lingüístico que mezcla elementos norteamericanos y mexicanos. La dinámica transnacional está opuesta a regionalismos como el chilango que Tenoch y Julio hablan, un dialecto que crea permanentes problemas de comunicación con la española Luisa.

Para resumir podemos constar que la doble estructura de la trama entre significados literales y alegóricos superpone incesantemente aspectos diferentes y hasta contrarios que forman una imagen profundamente heterogénea y ecléctica de la nación mexicana: entre elementos realistas y míticos, regionales y transnacionales, entre el campo y la ciudad, pasado colonial y política actual, machismo y matriarcado. Podemos referir a cómo el sociólogo constructivista Benedict Anderson (2006) define la nación en cuanto comunidad imaginada y comparte las mismas ideas sobre un terreno. Es evidente que Cuarón cita toda una serie de mitos fundacionales que representaban antaño la idea de México. En lugar de dar una visión sintética, sin embargo, pone en escena un país compuesto de diferentes épocas, áreas, clases, culturas e idiomas; en términos de Foucault, un espacio heterotópico y heterocrónico. Pudimos observar, no obstante, que la película no puede interpretarse como mero acto de destrucción o diseminación de los mitos fundacionales. El México de Cuarón es, en las propias palabras del director, un país adolescente a la búsqueda de su identidad entre fuerzas utópicas y conservadoras; una nación sin autoridad "paternal", cuyos representantes políticos están ausentes como los padres de los protagonistas.

\section{Bibliografía}

Acevedo-Muñoz, Ernesto. 2004. “Sex, Class, and Mexico in Alfonso Cuarón’s $Y$ tu mamá también". Film and History 34, n. ${ }^{\circ}$ 1: 39-48.

Alion, Yves. 2001. "Y tu mamá también: entretien avec Alfonso Cuarón”.L'Avant-Scene Cinema 507: 137-140.

Anderson, Benedict. 2006. Imagined Communities: Reflections on the Origin and Spread of Nationalism. London \& New York: Verso.

Baer, Hester. 2004. “Transnational Cinema and the Mexican State in Alfonso Cuarón's Y tu mamá también”. South Central Review 21: 150-168.

Börner, Klaus H. 1984. Auf der Suche nach dem irdischen Paradies. Zur Ikonographie der geographischen Utopie. Frankfurt/M.: Wörner.

Cuarón, Alfonso. 2001. Y tu mamá también (DVD). Madrid: Producciones Anhela. Freud, Sigmund. 1982a. "Das Ich du das Es". En Studienausgabe III, 273-330. Frankfurt/M.: Fischer. 
Freud, Sigmund. 1982b. "Zur Einführung des Narzißmus”. En Studienausgabe. Frankfurt/M.: Fischer.

Girard, René. 1978. Mensonge romantique et vérité romanesque. Paris: Grasset.

Girard, René. 1982. La violence et le sacré. Paris: Grasset.

Grimm, Reinhild. 1977. Paradisus Coelestis Paradisus Terrestris: Zur Auslegungsgeschichte im Abendland bis um 1200. München: Fink.

Grob, Norbert y Thomas Klein, editores. 2006. Road Movies. Mainz: Ventil.

Jung, Carl Gustav y Wolfgang Pauli. 1952. Naturerklärung und Psyche.Zürich: Rascher.

Kittler, Friedrich. 1977. "Das Phantom unseres Ichs und die Literaturpsychologie. E.T.A. Hoffmann-Freud-Lacan". En Urszenen. Literaturwissenschaft als Diskursanalyse und Diskurskritik, editado por Friedrich Kittler y Horst Turk, 139-166. Frankfurt/M.: Suhrkamp.

Lacan, Jacques. 1966a. "Le stade du miroir comme formateur de la fonction du Je". Écrits, 93-100. Paris: Seuil.

Lacan, Jacques. 1966b. “Du 'Trieb’ du Freud y du désir du psychanalyse”. En Écrits, 851-854. Paris: Seuil.

Lacan, Jacques. 1984 [1938]. Les complexes familiaux dans la formation de l'individu: essai d'analyse d'une fonction en psychologie. Paris: Navarin.

Lacan, Jacques. 1998. Les formations de l'inconscient. Le Séminaire V. Paris: Seuil.

Lahr-Vivaz, Elena. 2006. "Uncomsummated Fictions and Virile Voiceovers: Desire and the Nation in Y tu mamá también”. Revista de Estudios Hispánicos (St. Louis) 40, n. ${ }^{\circ} 1: 79-102$.

Mora, Sérgio de la. 2006. Cinemachismo: Masculinity and Sexuality in Mexican Cinema. Austin: University of Texas Press.

Pratt, Mary Louise. 2008. Imperial Eyes: Travel Writing and Transculturation. London: Routledge.

Rama, Angel. 1982. Transculturación narrativa en América Latina. México: Siglo XXI. Saldana-Portillo, María Josefina. 2005. "In the Shadow of NAFTA: Y tumamá también Revisits the National Allegory of Mexican Sovereignty”. American Quarterly 57, n. ${ }^{\circ}$ 3: 751-778.

Sommer, Doris. 1991. Foundational Fictions: the National Romances of Latin America. Berkeley: University of California Press.

Torres San Martín, Patricia. 2012. "La recepción del cine mexicano y las construcciones del género: ¿formación de una audiencia nacional?”. La Ventana 27: 58-103. Wolfzettel, Friedrich. 2003. Reisebericht und mythische Struktur (Aufsätze 1983-2003). Stuttgart: Winter. 